\title{
A NORMATIVELY NEUTRAL DEFINITION OF PATERNALISM
}

\begin{abstract}
By Emma C. Bullock
In this paper, I argue that a definition of paternalism must meet certain methodological constraints. Given the failings of descriptivist and normatively charged definitions of paternalism, I argue that we have good reason to pursue a normatively neutral definition. Archard's I9go definition is one such account. It is for this reason that I return to Archard's account with a critical eye. I argue that Archard's account is extensionally inadequate, failing to capture some cases which are clear instances of paternalism. I refine each of his three conditions, ultimately providing an improved definition of paternalistic interference. This revised definition meets specific methodological constraints, offering a definition that is both neutral between anti- and pro-paternalistic intuitions, but that also explains why paternalism is normatively significant. Specifically, this definition captures the conflict between interfering with an individual's choices and treating the individual benevolently, without making paternalism permissible or impermissible by definition.
\end{abstract}

Keywords: paternalism, intuition, normativism, descriptivism.

Paternalism is standardly taken to be a bad thing. Policies and practices are ruled out merely on the basis that they constitute paternalism ${ }^{1}$, and it is frequently claimed that paternalistic interferences wrongly treat adults as if they were children. ${ }^{2}$ Increasingly, however, paternalism is being defended as something that can be morally justified. ${ }^{3}$ In order to have a meaningful debate about the moral permissibility of paternalism, there is a need to clearly define the term. This is reflected in recent philosophical work on defining paternalism. ${ }^{4}$

This paper contributes the debate on how to define paternalism in two central ways. First, I provide an improved methodology for defining the concept by

\footnotetext{
${ }^{1}$ See Van Boom \& Ogus (2010: 3), Sjöstrand \& Helgesson (2008: I 18), Colgrove (2006: 2390), and Bennett (200I: 46r).

${ }^{2}$ See De Marneffe (2006: 68). Paternalism's sister notion, 'the nanny state' also has infantilizing connotations (Wiley, Berman and Blanke 20i3: 9o).

${ }^{3}$ See Conly (2013), Jansen \& Wall (2009), and Loewy (2005).

${ }^{4}$ For overviews, see Dworkin (2013) and Grill (2009).
} 
championing normative neutrality. I argue for this as a middle way between on the one hand descriptive accounts, which fail to capture paternalism as a normative concept, and on the other hand normatively charged definitions, which I argue are question begging.

Secondly, this paper provides a timely reassessment of Archard's (I990) normatively neutral definition of paternalism. In the following, I argue against each of Archard's three conditions for paternalism. First, I argue that a paternalistic intervention need not deny an individual's choice nor decrease the options available to her in order to be paternalistic. Secondly, I claim that A's belief that her behaviour promotes B's good does not need to be the main reason for the interference in order for it to count as paternalistic. Thirdly, I argue that a paternalistic interference need not discount B's belief that A's interference does not promote B's good.

There are two important advantages of the normatively neutral definition of paternalism I defend. First, the account captures clear cases of paternalism that are not captured by Archard's. Secondly, it meets well-motivated methodological constraints; the definition has the advantage that it is neutral between anti- and pro-paternalistic intuitions and so does not beg the question regarding the moral permissibility of paternalistic interferences, whilst capturing paternalism as a normative concept.

The focus of this paper is on defining paternalistic interferences between two individuals. For this reason, I do not comment on the nature of paternalistic interferences aimed at groups of people. Furthermore, this definition applies to individuals who meet the relevant standard for decision-making capacity and who are worthy of having their decisions respected. The nature of paternalistic interferences with children or incompetent persons is not considered. ${ }^{5}$

\section{METHODOLOGY}

One consideration to take into account when defining paternalism is whether or not the term should be defined normatively or descriptively. Descriptive definitions are defended on the basis that they are neutral between competing intuitions about the permissibility of paternalistic interferences. ${ }^{6}$ VanDeVeer's descriptive account, for instance, roughly defines paternalism as behaviour that aims to benefit a person contrary to her current preference, intention, or disposition (VanDeVeer i986: 22). Suppose, for example, that I snatch away

\footnotetext{
${ }^{5}$ These are classed as 'soft' paternalistic interferences. Soft paternalism does not usurp an individual's competently made decision and so is '... really no kind of paternalism at all' (Feinberg ı986: ı6). See also Gert \& Culver (ı976: 53).

${ }^{6}$ I focus on VanDeVeer's descriptivist definition (VanDeVeer 1986: 35). See also Parve (200I) and arguably, De Marneffe (2013: 74).
} 
a glass of water (which unbeknownst to you is poisoned) in order to prevent you from becoming ill by drinking it. I aim to benefit you, contrary to your current preference to drink the water, and so according to VanDeVeer act paternalistically. Note that VanDeVeer's definition has nothing to say as to whether this paternalistic interference is morally (im)permissible; whether or not it is morally (im)permissible will involve considerations aside from it being an instance of paternalism.

Descriptivist definitions are argued to be inadequate because they fail to capture paternalism as a normative concept. Grill argues that a definition of paternalism should have something to say about whether paternalism ought to be avoided or sought (Grill 2013: 43); just as a definition of 'harm' should capture its negative normative connotations, and 'friendship' its positive normative features, a definition of paternalism ought to capture the normative features that are associated with it. Since descriptivist definitions have nothing to say about the morally controversial nature of paternalistic interventions they fail to capture the meaning of the term.

Given the deficiency of descriptive accounts, commentators have tended to pursue 'normatively charged' definitions of paternalism. A definition is normatively charged when '. . whether or not something falls under the concept always counts for or always counts against doing that thing or being that way' (Grill 20I3: 3I). Notably, normatively charged definitions of paternalism tend to identify the concept as being intrinsically normatively negative and aim to capture the anti-paternalistic intuition that paternalistic behaviour is morally wrong. Shiffrin's negatively normatively charged definition of paternalism, for instance, aims to capture the anti-paternalistic intuition that '.. . paternalist doctrines and policies convey a special, generally impermissible, insult to autonomous agents' (Shiffrin 2000: 206). On Shiffrin's definition, it always counts against behaviour or an action when it falls under the concept of paternalism.

Arguably, an advantage of negatively normatively charged definitions of paternalism is that they accommodate the common idea that paternalism is pro tanto morally repugnant. ${ }^{7}$ In light of this, Grill argues that since the most common attitude towards paternalism is to reject it, absolutely or conditionally, an accurate definition of the concept should accommodate different forms of anti-paternalism (Grill 2007: 458). Although not offering a definition himself, Groll also argues that on the basis of widespread anti-paternalistic intuitions, an adequate definition of paternalism must make it 'reasonably clear why paternalism is presumptively impermissible' (Groll 2012: 7IO, 7II).

Nevertheless, there are at least two specific problems with negatively normatively charged definitions of paternalism. The first problem is that negatively normatively charged definitions entail that it is conceptually incoherent to

\footnotetext{
${ }^{7}$ See footnotes I and 2.
} 
think that paternalism is morally permissible (Coons and Weber 2013). Those who have pro-paternalistic intuitions will either have to argue that cases of paternalism do not exist (Grill 2013: 36) or concede that their intuitions are wrong. Both of these consequences are undesirable: it should be possible to have a discussion about the moral permissibility of a paternalistic interference, especially in view of emerging defences of them. ${ }^{8}$ Instead, a negatively normatively charged definition of paternalism changes the debate about the moral permissibility of paternalistic interferences to a debate about whether an interference counts as an instance of paternalism at all.

Proponents of negatively normatively charged definitions of paternalism object that their accounts do not imply that paternalism is necessarily impermissible. Rather, their definitions only imply that paternalism is pro tanto morally problematic. Shiffrin argues, for example:

... whether [paternalism] is always all-things-considered wrong will depend upon, among other things, one's view about how stringent (some) rights, and other forms of legitimate control, are, and how much weight they exert against the prospect of mistakes that may involve high levels of foregone welfare or other sorts of realised value. (Shiffrin 2000: 220, n.25)

Nonetheless, even if negatively normatively charged definitions only imply that paternalism is pro tanto impermissible it remains the case that it will always count against an intervention if it falls under the concept of paternalism. Negatively normatively charged definitions still deny that 'being paternalistic' can ever be a positive feature of a particular action. This denial, however, is controversial and a definition of paternalism should allow for its discussion. ${ }^{9}$

A second difficulty with negatively normatively charged definitions of paternalism is that they are constructed in order to capture anti-paternalistic intuitions. This is not an approach taken in other areas of philosophy. To illustrate the concern, consider demanding that an acceptable definition of utilitarianism must capture what the anti-utilitarian finds deplorable about it. Or, in the philosophy of mind, demanding that a definition of physicalism must side with dualist intuitions. It would be unreasonable to impose these definitional restrictions in other areas of philosophy, and it is equally unreasonable to require that a definition of paternalism captures anti-paternalistic intuitions, demanding - without argument - that the pro-paternalist gives up her intuitions about morally permissible instances of paternalism. ${ }^{10}$

\footnotetext{
${ }^{8}$ See footnote 3 .

${ }^{9}$ One could defend a negatively normatively charged definition that identifies paternalism as being prima facie wrong. However, this would still mean that the fact that an action is paternalistic will always count against that action until further analysis of the situation is carried out. This is something that pro-paternalists would want to deny. I would like to thank Andres Moles and Kalle Grill for discussion of this point.

${ }^{10}$ This is not to deny that there are theoretical objections to paternalism (see Darwall 2006; Mill 2008: 92; Quong 2011; and VanDeVeer I986: 445).
} 
It is true that paternalism, unlike utilitarianism and physicalism, has not developed as a name for a positive philosophical theory. Instead, paternalism is a term that has a 'pejorative connotation' (Schermer 2002: 17 ) ${ }^{11}$ and is standardly used to refer to interferences that are considered to be morally problematic. However, there are at least two reasons why the historical use of the term ought not to impose restrictions on the definition of the concept. First, the term can be and has been used in a positive way to describe interferences that are caring or 'honourable' (Archard 1994: 292). Secondly, regardless of the historical usage of the term, we should not define the concept in such a way that we are unable to have a meaningful debate with pro-paternalists. The mere fact that anti-paternalists have dominated the use of the term does not mean that paternalism should pick out something that is intrinsically morally unacceptable.

Rejecting both descriptive and negatively normatively charged definitions of paternalism leaves us with two methodological options. One option is to present a positively normatively charged account of paternalism, which would entail that whenever an action is paternalistic it is pro tanto morally permissible. But this would have undesirable consequences similar to those faced by negatively normatively charged accounts: (a) paternalistic interventions would always be pro tanto morally permissible forcing anti-paternalists to drop their intuitions, or to deny that the interferences they find objectionable are paternalistic; (b) it is methodologically misguided to suppose that a definition should aim to appease one side in a philosophical debate (in this case the pro-paternalist).

A better approach to defining paternalism is to adopt a strategy that remains neutral between anti- and pro-paternalistic intuitions, but that also captures paternalism as a normative concept. We might therefore think that an adequate definition of paternalism need not be normatively charged but that it need only clarify its normative features (Groll 2012: 710, 7II). What I will be referring to in the following as a normatively neutral definition will capture paternalism as a normative concept without forcing the conclusion that any instance of paternalism is morally wrong or right. The advantage of this account is that it offers a middle way between descriptivist and normatively charged definitions. Whilst it remains neutral on the moral permissibility of paternalism (as with descriptivist accounts), it identifies the aspects of paternalistic interferences that are morally controversial by including normative concepts within its definition.

Key examples of normatively neutral definitions of paternalism can be found in Archard (1990) and Clarke (2002). ${ }^{12,13}$ Archard's account attempts

${ }^{11}$ See Feinberg (1986: 4) and Blumenthal-Barby (2013: 210).

${ }^{12}$ Since Clarke himself admits that his account is identical to Archard's bar his omission of the third condition (Clarke 2002: 88), I focus on Archard's account in this paper. The importance of holding on to condition 3 will be elaborated in Section IV.

${ }^{13}$ Grill refers to these accounts as 'values-based' (Grill 2013: I9). 
to capture the normative conflict between interfering with an individual's choices and treating the individual benevolently without forcing the conclusion that paternalism is pro tanto morally right or wrong. Specifically, according to Archard, A's behaviour towards B is paternalistic iff it meets the following three conditions.

I. A aims to bring it about that with respect to some state(s) of affairs which concerns B's good, B's choice or opportunity to choose is denied or diminished.

2. A's belief that this behaviour promotes B's good is the main reason for A's behaviour.

3. A discounts B's belief that A's behaviour does not promote B's good (Archard I990: 36).

Note that Archard's definition does not settle one way or another whether actions that count as paternalistic according to it are pro tanto morally good or bad. An advantage of this definition is that it does not rule out debate on the moral permissibility of paternalism from the off; whether or not paternalism is permissible will depend on separate arguments about the value of free choice and our duties to promote the good of others. Archard's definition is also distinct from descriptive accounts because it captures the normative features of paternalism, it essentially involving a conflict between liberty (or autonomy) and well being (Grill 2013: 37).

Philosophical work on paternalism has tended to assume that the concept is negatively normatively charged and so direct engagement with Archard's account has been wanting. Given the advantages of a normatively neutral definition, it is high time for Archard's definition to be reassessed. In the following, I argue that Archard's account is extensionally inadequate, failing to capture some cases which are clear instances of paternalism. I refine each of his conditions, ultimately providing an improved normatively neutral definition of paternalistic interference.

\section{CONDITION (I)}

In order for A to act paternalistically towards B, condition (I) requires that A aims to deny or diminish the choices available to B with regard to B's good. ${ }^{14}$ Archard claims that condition (I) can be met in one of two ways. First, A can simply refuse to satisfy the option B has chosen and secondly, A can diminish

\footnotetext{
${ }^{14}$ It is sometimes denied that paternalism need always aim to influence choice (Gert and Culver 1976: 46; Hausman and Welch 2010: I26). Whilst there is not space for discussion here, I maintain that the counterexamples posed in the literature are better interpreted as interferences with an individual's hypothetical choice or as instances of soft paternalism.
} 
the options available to B by removing one or some of the options in her choice-set.

To clarify, consider a case in which you are hungry and I offer you a range of meals on my restaurant menu. The menu provides you with the options of (i) salad, (ii) baked potato, (iii) cheeseburger, or (iv) vegetable soup. Your choice of option (iii) can be straightforwardly denied when I refuse to give you the food you have selected. In order to diminish the options available to you, I could remove option (iii) from the menu. In this case, the options that are open to you are diminished from four to three; option (iii) is unknown to you and so not available for you to choose. Purposefully withholding information can therefore constitute a paternalistic interference. ${ }^{15}$

There is, however, at least one further way that an interference can count as paternalistic that condition (I) fails to account for, and this requires a reformulation of condition (I). Consider, for example, a situation in which A places a 'sin tax' on fatty foods. The food options available to B have been changed because the fatty foods that she finds desirable have become less affordable. A has interfered with B's options by making fatty foods harder to obtain, but A has not denied B the option of choosing to buy fatty foods, and neither has A diminished the range of foods available to $\mathrm{B}$. Nonetheless, this seems to be a plausible instance of paternalism because $\mathrm{A}$ has made it more difficult for $\mathrm{B}$ to obtain the foods she wants. Since condition (I) is too restrictive to account for such cases, it ought to be reformulated. The following change can be made to condition $(\mathrm{I})$ :

$\left(\mathrm{I}^{*}\right)$ A aims to bring it about that with respect to some state(s) of affairs which concerns

B's good, B's choice or opportunity to choose is denied, diminished or discouraged.

An option is discouraged if it is made more difficult for B to obtain it. $\left(\mathrm{I}^{*}\right)$ is therefore preferable to (I) because it accounts for this further type of paternalistic intervention.

It might be remarked that if a sin tax is high enough, then an option might no longer be available to $\mathrm{B}$. For this reason, it might be better to characterize these cases as diminishing choice. Consider a situation in which the sin tax placed by $\mathrm{A}$ is so high that the selection of fatty foods is now beyond B's monetary means. This can be reasonably construed as a paternalistic diminishing of the choices available to $\mathrm{B}$ and is thereby consistent with condition (I).

However, it is possible to make an option more difficult to obtain without removing it altogether ${ }^{16}$, and this is an alternative way of being paternalistic that should be acknowledged. In cases such as the one above, the sin tax is high enough to make the option less appealing to $\mathrm{B}$, but low enough that the option remains available to her should she choose to spend the extra money.

\footnotetext{
${ }^{15}$ See Pope (2004), New (1999: 70), and Clarke (2002: 84).

${ }^{16}$ See Sunstein \& Thaler (2008).
} 
In this sense, paternalistic intervention need not deny B's choice or decrease the options available to $\mathrm{B}$ in order to be paternalistic; an action can be paternalistic if an option is simply made more difficult to obtain. In order to include such cases in our definition of paternalism, we should reject condition (I) and adopt condition $\left(\mathrm{I}^{*}\right)$.

On condition $\left(\mathrm{I}^{*}\right)$ cases where A adds options to B's choice-set are nonpaternalistic. Archard explicitly denies that paternalism can involve adding options to B's choice-set, since paternalism ' . . . is about the supplanting of someone's choice of her good by that of the paternalist' (Archard I990: 38 [original emphasis]). Archard considers the negative effect of adding options to B's choice-set if we know B is unable to reasonably refuse certain offers, but he does not go so far as to say that the addition of an option can be paternalistic.

Shiffrin, however, has argued that freedom-enhancing behaviour can be paternalist, specifically in cases where A creates opportunities for B when B has declared she would prefer not to have more choice because, for instance, B finds too much choice overwhelming (Shiffrin 2000: 2I4). Such an interference is argued to be paternalistic because A overrides B's choice at $\mathrm{T}_{\mathrm{I}}$ to have fewer options available to her at T2. Whilst Shiffrin is correct that freedom-enhancing behaviour can be paternalistic, it is important to note that in Shiffrin's case it is not the increase in options at $\mathrm{T}_{2}$ that makes the action paternalistic. What makes the action paternalistic in this case is the denial of B's original choice at $T_{1}$ to have fewer options available to her at $T_{2}$. This kind of case of freedom-enhancing paternalism therefore meets condition $\left(\mathrm{I}^{*}\right)$ in the sense that it involves denying B's choice to have fewer options available to her regarding a particular decision in the future.

There is a remaining question as to whether incentives count as paternalistic. Incentives are often thought to be compatible with respecting individual free choice, and for this reason are considered to be non-paternalistic (Laliberté 2013: I-3; Scoccia 2008: 358). It might, however, be proposed that incentives can be paternalistic when a particular option is made irresistible to the chooser.

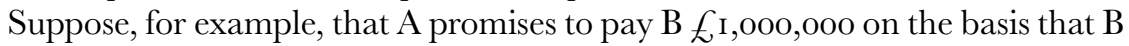
quits smoking. It might seem that in this case B doesn't really have a choice - A's offer is simply too good to refuse. Whilst it is not necessary for me to settle this debate, my proposal is that an incentive can be classed as paternalistic in so far as it denies, diminishes, or discourages the options available to B. An advantage of this stance is that it is compatible with the idea that incentives can be paternalistic in some instances; when 'irresistible' offers are made to individuals who are in desperate need of food, clothing, or medical care, an incentive could reasonably be described as paternalistic (Veatch 2003: 27). For example, imagine a case in which B is destitute, but has decided that she does not want to work for a particular company on the grounds that she disagrees with the company's values. If B has the option of (a) receiving unemployment benefit 
or (b) working for the company, option (b) might become irresistible if the wages offered to her by the company are raised significantly above the amount received through the benefit system. ${ }^{17}$ This incentive would be paternalistic since it would force B to take option (b) (given her desperate circumstances) despite her decision not to work for (b). If this is a case in which B's choice is being discouraged via an incentive, then it can be classed as an instance of paternalism. Whether it is an example of the denial or discouragement of B's choice or not is a matter for further debate. The claim here is that in either case we have not found an example of paternalism not meeting condition $\left(\mathrm{I}^{*}\right)$.

In addition to accounting for plausible cases of paternalistic interferences that are not captured by condition $(\mathrm{I})$, condition $\left(\mathrm{I}^{*}\right)$ remains normatively neutral; it identifies a normative feature of paternalism by defining the concept as involving an interference with B's choices (be it through the diminishment, denial, or discouragement of her choice), without forcing any conclusions as to whether such interferences are morally wrong or right. Recall that on VanDeVeer's descriptive definition, an interference counts as paternalistic if its aim is to benefit a person contrary to her current preference, intention, or disposition (VanDeVeer I986: 22). Whilst a paternalistic interference might be described as involving a contrast between A's beliefs about B's good and B's preferences, this definition fails to capture paternalism as essentially involving an interference with B's choices. Since it is an open debate between anti- and pro-paternalists as to whether an interference with another's choices is ever morally permissible a definition of paternalism ought to make reference to this feature of the concept. An advantage of condition $\left(\mathrm{I}^{*}\right)$ is that it captures this normative element of paternalism in a neutral way.

\section{CONDITION (2)}

Recall condition (2):

'A's belief that this behaviour promotes B's good is the main reason for A's behaviour.'

This condition states that in order for an action to be paternalistic A must have a particular motivation for interfering with an individual's choice-set. Specifically, she must aim to protect or promote that individual's good. The content of condition (2) can be broken down into two components: first, paternalistic interferences are characterized by a particular kind of motivation and secondly, the good that is promoted is that of the individual interfered with.

\footnotetext{
${ }^{17}$ As long as the incentive is motivated by the reason that it is for the individual's good to work for them (see condition $2^{*}$ ).
} 


\section{III.I Motivation}

Definitions of paternalism are standardly motive based, ${ }^{18}$ identifying a paternalistic act with reference to the benevolent reason(s) given for the interference. Motive-based definitions can be contrasted with effect-based definitions, which class interferences as paternalistic if they actually benefit the subject. Problematically, an effect-based definition cannot account for unsuccessful paternalistic interferences; an interference will only count as paternalistic if it successfully benefits the subject. Motive-based definitions have the advantage of accounting for unsuccessful paternalistic interferences because what makes an interference paternalistic on these accounts is the benevolent reason given for the interference. ${ }^{19}$ Since we can correctly characterize paternalism as being unsuccessful, I follow others in adopting a motive-based definition.

Archard's account is an example of a motive-based definition of paternalism, since condition (2) requires that A's belief that her interfering behaviour promotes B's good is the main reason for A's behaviour. However, an inadequacy of Archard's condition (2) is that A's belief that her interfering behaviour promotes B's good does not need to be the main reason for A's behaviour as stipulated in condition (2); it is enough that A's belief that her behaviour promotes B's good is a reason for A's behaviour, albeit one amongst others. Consider a case where $\mathrm{B}$ is a terrible drunk with a history of frittering away her money on alcohol. With this knowledge in mind, A decides to steal B's wages from her and give them to B's husband, $\mathrm{C}$, in order that $\mathrm{C}$ can use the money to pay the family's household and food bills. One of A's reasons for removing this choice from B - in line with condition (2) - is to protect B's health and her relationship with her family, but perhaps the main reason for A's behaviour is to protect the interests of B's family. This seems to be an instance of paternalistic interference where the main reason for A's behaviour is not the promotion of B's good.

The above example of paternalism sits well with the idea that most actions are usually motivated by several reasons at once. Policies are often supported by reasons of a number of kinds (Feinberg I986:I6) and legislation is often supported by a multiplicity of rationales (Husak 2000: 6I). ${ }^{20}$ Condition (2) should therefore be replaced with condition $\left(2^{*}\right)$ :

$\left(2^{*}\right)$ A's belief that this behaviour promotes B's good is a reason for A's behaviour

Paternalistic actions that are motivated by more than a concern for the individual's good count as instances of 'mixed paternalism'. With unmixed

${ }^{18}$ See Shiffrin (2000), Dworkin (1983), Scoccia (2008), and New (1999).

${ }^{19} \mathrm{I}$ leave it open as to whether the benevolent reason must be acknowledged by the interferer or whether the presence of that reason can be inferred from the interferer's behaviour. See Pope (2004) and Feinberg (1986).

${ }^{20}$ See Dworkin (1983: 20). 
paternalism, the only reason for the intervention is the promotion of the good of the individual concerned. ${ }^{21}$ The advantage of condition $\left(2^{*}\right)$ is that it allows both mixed and unmixed paternalism to count as paternalistic. On this condition, the benevolent motive can appear as one of many reasons, the only reason, or indeed the 'main' reason for a paternalistic intervention.

It might be argued that an interference does not count as paternalistic when B's good is not of primary concern to A. For example, suppose that A steals B's cigarettes for two reasons: her main reason is that she selfishly wants to smoke the cigarettes herself and her second, much weaker reason is that she thinks that removing the cigarettes from B will do B good. In this case, A's action is only weakly motivated by her belief that it will promote B's good and the interference might intuitively be thought of as non-paternalistic. However, to class this case as non-paternalistic is too restrictive. A weak benevolent reason might still be a necessary reason for the interference given the possibility that the interference: '. . . would not be motivated, all things considered, if it were not for the impact of paternalistic reasons' (Grill 2007: 445). For this reason, cases in which A only has a very weak reason to promote B's good should still be counted as paternalistic, the strength of the benevolent reason reflecting the degree to which the action is paternalistic.

An advantage of condition $\left(2^{*}\right)$ is that it allows for varying degrees of mixed paternalism in accordance with the strength of the benevolent reason motivating the interference. An intervention can be construed as being weakly paternalistic when the benevolent motive is a minimal reason for the interference. Furthermore, condition $\left(2^{*}\right)$ does not rule out the possibility that an interference can count as paternalistic if, as Archard suggests, the benevolent motive is the main reason for A's behaviour; interferences where the benevolent motive is the main reason for the interference can be treated as being strongly paternalistic. Condition $\left(2^{*}\right)$ thus allows that there can be varying degrees of paternalism depending on whether the paternalistic motivation is a major or minor reason for the intervention ${ }^{22}$ and that an interference counts as paternalistic: '. . regardless of the (relative) strength of that reason' (Grill 2007: 442).

Condition $\left(2^{*}\right)$ is a necessary condition for paternalistic interference. Condition $\left(2^{*}\right)$ thereby classes situations where A feels so strongly about C's good that she does not care whether the interference is detrimental to B's good as non-paternalistic. However, the requirement that the benevolent motive be present only applies to actual interferences. A stronger position might insist that an intervention is paternalistic iff it is true that the agent would not

21 '[Mixed paternalism] is justified partly by the aim of preventing people from suffering harm at their own hands... Unmixed paternalistic laws have no motive or reason other than preventing self-harm or consented-to harm from others' (Feinberg I986: 8); see also Pope (2004: 699).

${ }^{22}$ See Clarke (2002: 82). 
have performed this action in a counterfactual situation in which she lacks a paternalistic motive. ${ }^{23}$ This, however, would class as non-paternalistic any interference where the interferer had a very strong benevolent motive for interfering with the subject, but had strong enough reasons to interfere without it. Imagine, for instance, that in the case of the drunk discussed above, A has a very strong motive for protecting or promoting B's good but in the counterfactual situation where A's concern for B's good is absent A's reasons for interfering on the basis of protecting C's good are strong enough to motivate A to interfere. Intuitively, the actual interference counts as paternalistic, regardless as to whether the interference would have been performed without the benevolent motive towards B in the counterfactual situation.

\section{III.2 Intended beneficiaries}

On both condition (2) and condition $\left(2^{*}\right)$, the intended beneficiary of the interference is identical to the individual whose choices have been interfered with. On this account of paternalism, when A interferes with B's choice [in line with condition $\left.\left(\mathrm{I}^{*}\right)\right]$, A does so for the reason that this behaviour will promote B's good. The demand that paternalistic interference must aim to protect or promote the good of the individual interfered with has been, until recently, central to accounts of paternalistic interference. ${ }^{24}$

According to Shiffrin, however, the paternalist need not be motivated by a concern for the interests or welfare of the paternalistically treated agent at all (Shiffrin 2000: 215, 216). Shiffrin claims that an intervention can be paternalistic simply if it involves an interference with '... the agent's own legitimate domain of judgement or action' (Shiffrin 2000: 216). Shiffrin's point can be understood by returning to the earlier case of $\mathrm{B}$, the drunk. This example was used to illustrate that it is sufficient for condition $\left(2^{*}\right)$ that the promotion of B's good is $a$ reason for the interference, even if the main reason for the interference is to protect the interests of B's family. According to Shiffrin, A's interference with B will count as paternalistic even if the only reason for A's interference is to protect the interests of B's family. What makes it paternalistic is that A is interfering with B's domain of agency, not that A is aiming at promoting B's good. ${ }^{25}$

Shiffrin claims that the reason for adopting this broader account of paternalism is that a sharp line cannot be drawn between interferences that are aimed at promoting the individual's good and interferences that are motivated by different reasons. What is relevant in all such cases is that the domain over

${ }^{23}$ See De Marneffe (2006: 74, n.I6).

${ }^{24}$ See Gert \& Culver (1976: 50) and Pope (2004: 683, 684).

${ }^{25}$ We might refer to Shiffrin's suggestion as an example of impure paternalism, where impure paternalism means that the benefited class is not identical to the class of persons whose liberty is restricted (see Dworkin 2010; Pope 2004: 702). 
which the individual has legitimate authority has been interfered with (Shiffrin 2000: 218). However, there is no reason to think that such a sharp line needs to be drawn in order to have a useful concept of paternalism. Just because a concept has vague boundaries does not mean it is useless, or should be rejected. ${ }^{26}$ Concepts such as red, heap, child, bald, person, and health are perfectly acceptable despite having vague boundaries (Sainsbury 1996). Moreover, Shiffrin has not given us a reason to think that an adequate boundary cannot be drawn. It is easy to see that such a distinction can be made. For example, Mill's harm principle allows for interference with an individual's liberty when that individual's behaviour will harm the interests of others (Mill 2008: 83). As a result, the state is permitted to interfere with an individual's choices: '[a]s soon as any part of the person's conduct affects prejudicially the interests of others' (Mill 2008). A relevant distinction can seemingly be drawn between interferences that limit individual liberty for the sake of protecting others from harm and interferences that limit individual liberty for the sake of protecting that individual from harm. Intuitively, we do not want to count the harm principle as paternalistic. Paternalism seems to involve a distinctive kind of interference, and so it is worth drawing a line at least between these two types of interference, even if that line has vague boundaries.

A further advantage of condition $\left(2^{*}\right)$ is that it captures paternalism as a normative concept without begging any questions regarding its moral permissibility. Specifically, condition $\left(2^{*}\right)$ refers to a feature of paternalism that often comes under dispute in debates over the moral permissibility of paternalistic interferences, namely, the motivation to promote an individual's good. ${ }^{27}$ Discussion over the moral permissibility of paternalism will depend, in part, on the nature of the individual's good and whether or not a separate individual is justified in promoting it. Whilst those opposed to paternalism might argue that an individual's good is grounded in the exercise of her autonomy, ${ }^{28}$ or the satisfaction of her preferences of which she has privileged access to ${ }^{29}$ (making paternalistic interferences incoherent), those defending paternalism can cite objective accounts of well being ${ }^{30}$ or perfectionist theories of value ${ }^{31}$ as constituting that individual's good. On the latter accounts, it is at least prima facie permissible for an individual to paternalistically promote an individual's good. A benefit of condition $\left(2^{*}\right)$ is that by capturing this feature of paternalism

\footnotetext{
${ }^{26}$ This is at least the case on the widely accepted linguistic theory of vagueness. See Sider (2003: 125), Lewis (1986: 212), Dummett (1978: 260), Fine (1975: 265-300), and Russell (เ923: $84-92)$.

${ }^{27}$ See Archard (1994), Feinberg (1986: 5), Dworkin (1983), Grill (2007), and Groll (2014).

${ }^{28}$ See Feinberg (I986), Pellegrino \& Thomasma (I988), Faden \& Beauchamp (I986), Savulescu (2003), and Epstein (I995).

${ }^{29}$ For example Tännsjö (2002), Veatch (2003), and Mill (2008).

${ }^{30}$ See Scanlon (1993), Arneson (1999), and Varelius (2003).

${ }^{31}$ See Quong (201I), Yuracko (2003), and Chan (2000).
} 
it identifies the concept as normative without reaching any conclusions about its moral permissibility.

VanDeVeer's descriptive account speaks of 'benefiting' an individual (VanDeVeer ig86: 22). Since one might use the terms 'benefit' and 'good' interchangeably by simply using the phrase 'benefiting an individual' to mean 'promoting an individual's good', ${ }^{32}$ VanDeVeer could be seen to have included a normative notion within what is often taken to be a descriptive definition of paternalism. A central argument of this paper is that descriptive definitions should not be pursued because it is difficult to see how one could provide a completely descriptive definition of something that is essentially normative. The suggestion that VanDeVeer fails to capture paternalism in completely descriptive terms supports this general thesis and does not undercut the advantages of the normatively neutral definition defended here.

\section{CONDITION (3)}

Condition (3) requires that in order for A's intervention to be paternalistic, A must discount B's belief that A's behaviour does not promote B's good. At first glance, this condition seems correct since if $\mathrm{B}$ believes that A's behaviour does not promote her good then, assuming $\mathrm{B}$ is rational, we can infer that $\mathrm{B}$ does not want the interference to take place. Indeed, a common assumption that is made when defining paternalism is that the interference must be contrary to the subject's will. ${ }^{33}$ This tension between what $\mathrm{A}$ and $\mathrm{B}$ believe is central to definitions of paternalism, which broadly characterize paternalism as the usurpation of B's choice: if B's choice is to be usurped, then it seems to follow that B must believe that A's interference is in some way unwarranted.

However, the claim that A must discount B's belief that A's interference does not promote B's good, as stated in condition (3), is problematic. The first inadequacy with condition (3) is that an individual need not be aware that a paternalistic intervention has taken place, and so need not have the belief that A's interference does not promote her good. This can be elucidated by returning to the example above in which A steals B's money in order to support B's family. Let us suppose that A steals the money when B is so drunk that she fails to notice the theft. When B awakes the next day and finds her money missing she simply assumes that she spent the money on drink and so has no knowledge of A's interference. It follows that B lacks the relevant belief, as stipulated by condition (3), that A's interference does not promote her good. Since this is a plausible case of paternalistic interference, we should adopt the reformulated condition $\left(3^{*}\right)$ :

\footnotetext{
32 Thank you to an anonymous reviewer for highlighting this.

${ }^{33}$ Groll refers to this as the 'contrary to will criterion' (2012: 696).
} 
$\left(3^{*}\right)$ A discounts the belief that B would have if she were relevantly informed of A's interference with her choices, that A's interference does not promote B's good

If it is possible for an individual to be ignorant that she is being treated paternalistically, then it follows that it is possible that she does not believe that $\mathrm{A}$ is interfering with her choices. For this reason, condition $\left(3^{*}\right)$ is an improvement on condition (3).

Nonetheless, condition $\left(3^{*}\right)$ is still too strong a constraint on paternalistic interference. This is because, on the assumption that an individual might be able to freely make choices that are risky or harmful, it is plausible that an individual can knowingly make a decision that is not for her own good. ${ }^{34}$ Suppose that $\mathrm{B}$ decides to take up the habit of smoking and that $\mathrm{B}$ is aware that the decision does not contribute to her good. ${ }^{35}$ When A steals B's cigarettes $\mathrm{B}$ recognizes that $\mathrm{A}$ is acting for her good but nonetheless refuses to condone A's interference with her choice. In this case, B makes a decision which she is fully aware fails to protect or promote her good. ${ }^{36}$ The possibility of such a case is consistent with anti-paternalism, which allows individuals to make harmful or imprudent decisions even whilst being aware that they are doing so: take for instance Mill's example of an individual attempting to cross a bridge that he is unaware is unsafe. If I were to inform Mill's bridge crosser that the bridge he is about to cross is unsafe and he competently decides to cross the bridge anyway - fully aware that it is an imprudent decision - then, at least according to Mill, I am not permitted to interfere with him as this would be paternalistic. ${ }^{37}$ Interference with an individual's choice can thus be paternalistic even if the choice that is supplanted is not one that the individual regards as being for her own good.

Another way of expressing this inadequacy with condition $\left(3^{*}\right)$ is to acknowledge that a paternalistic interference can be consistent with the subject's own values (Coons and Weber 2013: 10). For instance, Shiffrin argues that paternalism can occur when the subject agrees with the outcome, but is too weak-willed to carry out the act himself: the paternalist and the subject can be in agreement about the good of the outcome aimed for in cases where the paternalist is motivated by a distrust of the subject's ability to pursue that good on his own (Shiffrin 2000: I I5). Pope also denies that a paternalistic agent must

\footnotetext{
${ }^{34}$ Whether it is possible to knowingly make a choice that you believe is not for your own good is disputed (see Plato I96r). Condition ( $\left.3^{*}\right)$ aims to encompass the plausible view that agents can act against their own interests, without begging any questions regarding its possibility.

${ }^{35}$ Here, B's 'good' is identified with B's 'overall good.'

${ }^{36}$ The point of the case is to illustrate that it is possible for someone to act against their own conception of the good. If possible, then B can believe that A's interference is for her own good but still reject the interference.

37 'If either a public officer or anyone else saw a person attempting to cross a bridge which had been ascertained to be unsafe [...] he ought, I conceive, to be only warned of the danger; not forcibly prevented from exposing himself to it' (Mill 2008: I06, I07).
} 
act contrary to the subject's preferences, only that she must act independently of them (Pope 2004: 720). For Pope, an act is paternalistic whenever the agent ignores the individual's preferences or whenever she acts unwittingly of them. This supposition allows that, by chance, A and B's beliefs about B's good may align. ${ }^{38}$

In order to proceed with a definition of paternalism we have two options: either remove (3)-style conditions altogether or develop a (3)-style condition that does not rely on B's belief that A's interference does not promote her good. The first option is unattractive, since the resulting definition of paternalistic interference would be subject only to conditions $\left(\mathrm{I}^{*}\right)$ and $\left(2^{*}\right)$. Consequently, any interference in which A denies, diminishes, or discourages B's choice on the basis of a reason that this behaviour promotes B's good would count as paternalistic. ${ }^{39}$ However, a definition of paternalism that is reliant on only conditions $\left(\mathrm{I}^{*}\right)$ and $\left(2^{*}\right)$ allows for cases which are intuitively non-paternalistic. Take for example a case in which B is critically ill and so asks her doctor, A, to make all of her medical decisions. When A acts on this request, she restricts B's options to the medical option that she believes is for B's good [condition $\left.\left(\mathrm{I}^{*}\right)\right]$. Moreover, her reason for doing this is that this behaviour promotes B's good, since - not only is it the best medical treatment - but it also respects B's wishes [condition $\left.\left(2^{*}\right)\right]$. Typically, we do not regard authorized interferences with our choices as being constitutive of paternalism. Since conditions $\left(\mathrm{I}^{*}\right)$ and $\left(2^{*}\right)$ by themselves class as paternalistic interferences that intuitively are not paternalistic, a third condition for paternalism is required. Condition (3) must be reformulated, rather than rejected altogether.

The above objection to eliminating (3)-style conditions highlights a significant feature of paternalistic intervention, specifically, that A's interference with $\mathrm{B}$ cannot be paternalistic if $\mathrm{B}$ has authorized it. An interference can be paternalistic even if the individual has a contemporaneous preference for the outcome: what is relevant for paternalism is that the subject lacks a preference for the interference itself. A useful starting point for developing condition (3) is therefore to focus on the presence or absence of B's authorization.

Unfortunately, the presence or absence of B's authorization is insufficient for paternalistic interference since - as previously shown - A's interference with

\footnotetext{
${ }^{38}$ See also Groll (2012: 707), who argues that an individual's will can be disrespected even if the paternalist acts in accordance with that individual's will.

${ }^{39}$ Clarke proposes that Archard's third condition should be abandoned. According to Clarke, cases where A and B's beliefs about the good align do not count as paternalistic because A's reason for acting in these cases is to give B what B desires. For Clarke, this fails to meet condition (2) since $\mathrm{A}$ is attempting to get $\mathrm{B}$ what she wants rather than attempting to promote her good. As such, this type of case does not count as paternalistic. Clarke therefore argues that Archard's third condition is unnecessary (Clarke 2002: 88, 89). It is worth noting, however, that Clarke is only correct to the extent that a desire-satisfaction account of B's good is not true. If it turns out that B's good is identical to the satisfaction of B's desires, then cases where A and B's belief about the good align would count as paternalistic.
} 
B's choices might be unknown to B. This leaves open the possibility that B would authorize A's interference with her choices were she to be informed. Since in a hypothetical situation B would authorize the behaviour, then it seems as though the action is not paternalistic. A better reformulation of condition (3) would account for the hypothetical situation in which B would authorize the interference were she to be relevantly informed. Condition (3) should thus be reformulated to $\left(3^{* *}\right)$ :

$\left(3^{* *}\right)$ A discounts the fact that $\mathrm{B}$ would not authorise the interference if $\mathrm{B}$ were to be relevantly informed of A's interference with her choices.

This reformulation is compatible with Groll's recent work on this aspect of paternalism. ${ }^{40}$ According to Groll, what matters when deciding whether someone has acted paternalistically is not whether the intervention is against the individual's will, but '.. whether she has treated the will of the other person as decisive in determining how she should act' (Groll 2012: 696 [my emphasis]). An individual's will is decisive when she has authority over that decision (Groll 2012: 699-706). The thought that paternalism involves a failure to respect an individual's will, rather than directly conflicting with it, can be brought out with an intuitive example. Consider a case in which it dawns on $\mathrm{B}$ that she has been spending too much time watching television programmes and that it would be for her own good to watch less television and instead practice her violin. B returns home and - bypassing the television set - settles down to some violin practice. Unbeknownst to B, her partner A has independently decided that watching less television would be for B's own good and so unplugs the aerial from the television set, knowing that $\mathrm{B}$ would presume that the television was broken were she to switch it on. Let us now suppose that B never switches on her television and so never discovers that it is not working, nor does she ever discover that $\mathrm{A}$ has unplugged the aerial. We can imagine that were $\mathrm{B}$ to discover that $\mathrm{A}$ had interfered with her opportunity to watch television in this way she would not authorize A's behaviour. It is her television and her decision - even if she agrees with A that not watching television is for her own good. Intuitively, this is a case of paternalism because A discounts the fact that $\mathrm{B}$ would not authorize the interference if $\mathrm{B}$ were to be relevantly informed of A's interference with her choice. What is therefore relevant for paternalistic interference is not B's belief that A is failing to act for her good as Archard presents in condition (3), but rather that the interference is not authorized by $\mathrm{B}$ as reformulated in condition $\left(3^{* *}\right) .{ }^{41}$

\footnotetext{
${ }^{40}$ Groll doesn't offer a full analysis or definition of paternalism but instead focuses in depth on the intuition that paternalistic interference should be contrary to the subject's will (Groll 2012: 693).

${ }^{41}$ It could be argued that an interference is paternalistic even with the presence of B's authorization. For example, if A hides B's cigarettes for B's own good, then A's actions are
} 
Again, an advantage of condition $\left(3^{* *}\right)$ is that it remains normatively neutral with regard to the permissibility of paternalism whilst capturing it as a normative concept. The normative feature that is captured under this condition is the individual's authority over her will. Whether or not an act of paternalism is permissible will hinge on whether the individual's authority is absolute or violable. Groll, for instance, suggests that this type of authority 'silences all other considerations', implying that paternalism is pro tanto morally impermissible since all other normative considerations are silenced. Given that the aim of this paper is to formulate a normatively neutral definition of paternalism, reference to B's authorization is used here to identify a position of power without making a judgement as to whether this authority has any moral force. This usage of the term is coherent since it is possible for an individual's prima facie authority to be overridden by other authorities in certain contexts. For instance, a parent's authority over her child might be interfered with by a government authority should that child be harmed under her care. It is nonetheless plausible to speak of the parent's authority in terms of her relationship with her child without forcing any conclusions as to whether that authority has moral force in any given situation. The advantage of condition $\left(3^{* *}\right)$ is that it is neutral as to whether the individual's authority is inviolable whilst capturing paternalism as a normative concept.

Note that a descriptive definition has nothing to say about the relationship between paternalism and individual authority. Indeed, whether an action 'benefits a person contrary to her current preference, intention, or disposition' fails to pick out that the action is normatively significant. One reason it is normatively significant is that it involves an interference with the individual's prima facie authority over her will. Given that condition $\left(3^{* *}\right)$ picks out this normative feature without reaching any conclusions as to whether the individual's authority has any moral force in a given circumstance, and that it captures cases of paternalism unaccounted for by condition (3), condition $\left(3^{* *}\right)$ should be adopted.

\section{GONCLUSION}

The aims of this paper have been twofold. The first was to motivate and defend the adoption of a normatively neutral definition of paternalism. In the light of

paternalistic even though A has been authorized to behave in this way because he is limiting B's options. My suggestion is that interferences that are carried out with prior authorization at most count as soft paternalistic interferences since in order to make sense of the efficacy of B's precedent authorization at $\mathrm{T}_{\mathrm{I}}$ we should characterize $\mathrm{B}$ as being in some way incompetent to make a decision at $\mathrm{T}_{2}$. Alternatively, if $\mathrm{B}$ no longer authorizes the intervention at $\mathrm{T}_{2}$ the example will be one of hard paternalistic interference. I would like to thank an anonymous reviewer for helping me develop this thought. 
this, the second aim was to provide a much needed critical reassessment of Archard's I99o normatively neutral definition. Throughout this paper, I have presented cases which give us reason to reject Archard's conditions for paternalistic interference in favour of conditions $\left(\mathrm{I}^{*}\right),\left(2^{*}\right)$, and $\left(3^{* *}\right)$. I would like to put these revised conditions forward as necessary and sufficient for paternalistic interference. Accordingly, A's behaviour towards B is paternalistic iff:

$\left(\mathrm{I}^{*}\right)$ A aims to bring it about that with respect to some state(s) of affairs which concerns B's good, B's choice or opportunity to choose is denied, diminished or discouraged

$\left(2^{*}\right)$ A's belief that this behaviour promotes B's good is a reason for A's behaviour.

$\left(3^{* *}\right)$ A discounts the fact that $\mathrm{B}$ would not authorise the interference if $\mathrm{B}$ were to be relevantly informed of A's interference with her choices.

There are two central advantages to this definition. First, the account captures clear cases of paternalism that are not captured by Archard's. Secondly, it meets the methodological constraints outlined in Section I. Unlike normatively charged definitions, the definition above has the advantage that is neutral between anti- and pro-paternalistic intuitions and thereby avoids reaching any conclusions regarding the moral permissibility of paternalism. Unlike descriptive accounts, my normatively neutral definition picks out the relevant normative features of the concept. Specifically, it identifies paternalism as a normative concept by making reference to $\left(\mathrm{I}^{*}\right)$ the interference involved, $\left(2^{*}\right)$ the individual's good, and $\left(3^{* *}\right)$ the individual's authority. Throughout the paper, I have indicated ways in which these conditions might be interpreted in order to allow for anti- or pro-paternalism.

By defining paternalism in terms of these three conditions, the definition also provides a context in which to stage the perennial debate between antiand pro-paternalists regarding the absolute value of autonomy (condition $\mathrm{I}^{*}$ and condition $3^{* *}$ ) versus the importance of well being (condition $\left.2^{*}\right)$. I have not discussed whether or not paternalism can ever be morally justified on the basis of conditions $\left(\mathrm{I}^{*}\right),\left(2^{*}\right)$, and $\left(3^{* *}\right)$. Indeed, the central motivation of this paper was to remain neutral on the moral permissibility of paternalism in order to allow for a meaningful debate between anti- and pro-paternalists. A full analysis of the repercussions of the definition of paternalism presented here for its potential justification must be pursued elsewhere, although it is hoped that this improved normatively neutral definition will provide some much needed clarity in future debates concerning its moral acceptability. ${ }^{42}$

\footnotetext{
${ }^{42}$ I would like to thank a number of friends and colleagues for their comments on earlier drafts. In particular, Philip Goff, Heather Widdows, Iain Law, Kalle Grill, Andres Moles, Michael Cholbi, Tom Walker, Nicolas Cornell, Peter Schaber,Johannes Drerup, Danny Scoccia, and Kirk Surgener. I would also like to thank the participants of the MANCEPT workshop on Paternalism
} 


\section{REFERENCES}

Archard, D. (1990) 'Paternalism Defined', Analysis, 50: 36-42.

— (1994) 'For Our Own Good', Australasian fournal of Philosophy, 72: 283-93.

Arneson, R.J. (1999) 'Human Flourishing Versus Desire Satisfaction', Social Philosophy and Policy, I6: II3-42.

Bennett, R. (200I) 'Antenatal Genetic Testing and the Right to Remain in Ignorance', Theoretical Medicine, 22: 4 6I-7I.

Blumenthal-Barby,J. (2013) 'A Psychological Defense of Paternalism', in C. Coons and M. Weber (eds) Paternalism: Theory and Practice, 197-215. New York, NY: Cambridge University Press.

Chan, J. (2000) 'Legitimacy, Unanimity, and Perfectionism', Philosophy \& Public Affairs, 29: 5-42.

Clarke, S. (2002) 'A Definition of Paternalism', Critical Review of International Social and Political Philosophy, 5: 8I-9I.

Colgrove, J. (2006) 'The Ethics and Politics of Compulsory HPV Vaccination', The New England Fournal of Medicine, 355: 2389-9I.

Conly, S. (2013) Against Autonomy: Fustifying Coercive Paternalism. Cambridge: CUP.

Coons, C. and Weber, M., eds (2013) 'Introduction: Paternalism-Issues and Trends', in Paternalism: Theory and Practice, Io-35. New York, NY: Cambridge University Press.

Darwall, S. (2006) 'The Value of Autonomy and the Autonomy of the Will', Ethics, ir6: 263-84.

De Marneffe, P. (2006) 'Avoiding Paternalism', Philosophy and Public Affairs, 34: 68-94. (2013) 'Self-Sovereignty and Paternalism', in C. Coons and M. Weber (eds) Paternalism: Theory and Practice, 67-8I. New York, NY: Cambridge University Press.

Dummett, M. (1978) Truth and Other Enigmas. London: Duckworth.

Dworkin, G. (1983) 'Paternalism', in R. Sartorius (ed.) Paternalism, I9-34. Minneapolis: University of Minnesota Press.

- (2010) 'Paternalism', in E.N. Zalta (ed.) The Stanford Encyclopaedia of Philosophy $<$ http://plato.stanford.edu/archives/sum2oro/entries/paternalism/ > accessed 2 November 2013 .

- (2013) 'Defining Paternalism', in C. Coons and M. Weber (eds) Paternalism: Theory and Practice, 36-49. New York, NY: Cambridge University Press.

Epstein, R.A. (1995) 'The Harm Principle - And How It Grew', The University of Toronto Law Fournal, 45: 369-417.

Faden, R.R. and Beauchamp, T.L. (I986) A History and Theory of Informed Consent. Oxford: OUP. Feinberg, J. (1986) Harm to Self: The Moral Limits of the Criminal Law. Oxford: OUP.

Fine, K. (1975) 'Vagueness Truth and Logic', Synthese, 30: 265-300.

Gert, B. and Culver, C.M. (I976) 'Paternalistic Behaviour', Philosophy \& Public Affairs, 6: 45-57.

Grill, K. (2007) 'The Normative Core of Paternalism', Res Publica, I3: 44I-58.

(2009) 'Anti-Paternalism and Public Health Policy', PhD thesis, Royal Institute of Technology, Stockholm.

- (2013) 'Normative and Non-normative Concepts: Paternalism and Libertarian Paternalism', in D. Strech, I. Hirschberg and G. Marckmann (eds) Ethics in Public Health and Health Policy, 27-46. Netherlands: Springer.

Groll, D. (2012) 'Paternalism, Respect and the Will', Ethics, I22: 692-720.

- (2014) 'Medical Paternalism - Part 2', Philosophy Compass, 9: I94-203.

Hausman, D.M. and Welch, B. (2010) 'Debate: To Nudge or Not to Nudge', The fournal of Political Philosophy, 18: 123-36.

Husak, D.N. (2000) 'Liberal Neutrality, Autonomy and Drug Prohibitions', Philosophy \& Public Affairs, 29: 43-80.

Jansen, L.A. and Wall, S. (2009) 'Paternalism and Fairness in Clinical Research', Bioethics, 23: I72-82.

and Libertarian Paternalism, University of Manchester (September 2013), and members of staff at the School of Philosophy, Australian National University, the Department of Philosophy, Central European University, and the Department of Philosophy at King's College London, for their invaluable feedback on the paper and for their encouragement. 
Laliberté, M. (2013) 'Strings Attached: Untangling the Ethics of Incentives', fournal of Bioethical Inquiry, I0: II 5 -7.

Lewis, D. (I986) On the Plurality of Worlds. Oxford: Blackwell Publishing.

Loewy, E.H. (2005) 'In Defense of Paternalism', Theoretical Medicine and Bioethics, 26: 445-68.

Mill, J.S. (2008) On Liberty. Oxford: OUP.

New, B. (I999) 'Paternalism and Public Policy', Economics and Philosophy, I5: 63-83

Parve, V. (200I) 'Value-Neutral Paternalism', in R. Vihalemm (ed.) Estonian Studies in the History and Philosophy of Science, 219-27. Netherlands: Springer.

Pellegrino, E.D. and Thomasma, D.C. (I988) For the Patient's Good: The Restoration of Beneficence in Health Care. New York, NY: Oxford University Press.

Plato, (I96I) 'Protagoras', in E. Hamilton and H. Cairns (eds) The Collected Dialogues of Plato. 308-52. Princeton: Princeton University Press.

Pope, T. (2004) 'Counting the Dragon's Teeth and Claws: The Definition of Hard Paternalism', Georgia State University Law Review, 20: 659-722.

Quong, J. (201 I) Liberalism without Perfection. Oxford: OUP.

Russell, B. (1923) 'Vagueness', The Australasian Fournal of Philosophy and Psychology, I: 84-92.

Sainsbury, R. M. (1996) 'Concepts without Boundaries', in R. Keefe and A. Smith (eds) Vagueness: A Reader, 25I-64. Cambridge (MA): MIT Press.

Savulescu, J. (2003) 'Is the Sale of Body Parts Wrong? Fournal of Medical Ethics, 29: I38-9.

Scanlon, T. (1993) 'Value, Desire and Quality of Life', in M. C. Nussbaum and A. Sen (eds) The Quality of Life, 185-200. Oxford: Clarendon Press.

Schermer, M. (2002) The Different Faces of Autonomy: Patient Autonomy in Ethical Theory and Hospital Practice. London: Kluwer Academic Publishers.

Scoccia, D. (2008) 'In Defense of Hard Paternalism', Law and Philosophy, 27: 351-8I.

Shiffrin, S.V. (2000) 'Paternalism, Unconscionability Doctrine, and Accommodation', Philosophy EP Public Affairs, 29: 205-50.

Sider, T. (2003) Four Dimensionalism: An Ontology of Persistence and Time. Oxford: OUP,

Sjöstrand, M. and Helgesson, G. (2008) 'Coercive Treatment and Autonomy in Psychiatry', Bioethics, 22: II $3-20$.

Sunstein, C.R. and Thaler, R. (2008) Nudge: Improving Decisions about Health, Wealth, and Happiness. New Haven: Yale University Press.

Tännsjö, T. (2002) Coercive Care: Ethics of Choice in Health \& Medicine, London: Routledge.

Van Boom, W.H. and Ogus, A. (2010) 'Defining and Balancing Autonomy V. Paternalism,' Erasmus Law Review, 3: I-5.

VanDeVeer, D. (1986) Paternalistic Intervention: The Moral Bounds of Benevolence. Princeton: Princeton University Press.

Varelius, J. (2003) 'Autonomy, Subject-Relativity, and Subjective and Objective Theories of WellBeing in Bioethics', Theoretical Medicine, 24: 363-79.

Veatch, R.M. (2003) 'Why Liberals Should Accept Financial Incentives for Organ Procurement', Kennedy Institute of Ethics Fournal, I3: 19-36.

Wiley, L., Berman, M. and Blanke, D. (2013) 'Who's Your Nanny? Choice, Paternalism and Public Health in the Age of Personal Responsibility', Journal of Law, Medicine E Ethics, 41: 88-9I.

Yuracko, K. (2003) Perfectionism and Contemporary Feminist Values. Indiana: Indiana University Press.

\section{Central European University, Hungary}

